\title{
Un aplauso y dos críticas al agro colombiano
}

\author{
Héctor Guillermo Osío Uribe \\ Ariel Emilio Cortés Martínez
}

\author{
Autores \\ Héctor Guillermo Osío Uribe \\ Ingeniero de sistemas de la Universidad EAFIT, magíster en administración \\ pública de la ESAP, magíster en Doctrina Social de la Iglesia, de la Pontificia \\ Universidad de Salamanca. Centro de Estudios Juan Pablo II. Vinculado al \\ ICBF en el área de tecnología. \\ osio777@gmail.com
}

\section{Ariel Emilio Cortés Martínez}

Administrador público de la ESAP, médico cirujano de la Universidad Nacional, magíster en economía de la Pontifica Universidad Javeriana, magíster en dirección y administración de servicios sanitarios de la Universitat Pompeu Fabra, doctor en epidemiología y salud pública de la Universidad Rey Juan Carlos, doctorando en ciencias de la salud de la Universidad de Sevilla. Actualmente profesor investigador asistente en el área de salud del Departamento de Administración de la Facultad de Ciencias Económicas y Administrativas de la Pontificia Universidad Javeriana.

ariel.cortes@javeriana.edu.co"

Palabras clave

Mínimos vitales, seguridad alimentaria, dignidad humana, producción de alimentos, seguridad humana.

Keywords

Minimum Vital Elements, Food Security, Human Dignity, Food Production, Human Security.

JEL: H, H11, 0, 043, Q1, Q18.

Fecha de recepción: 12-11-15

Fecha de aprobación: 21-04-16

Cómo citar este atículo

Osío Uribe, H.G. y Cortés Martínez A. E. (2017). Un aplauso y dos críticas al agro colombiano. Administración y Desarrollo, 47(1), 83-96.
Resumen

- Son posibles los mínimos vitales en la Colombia bicentenaria? Una ¿investigación abierta aborda esta pregunta y motiva la escritura de críticas y otro tipo de textos que propongan una solución inmediata al tema del hambre en Colombia. El quid de la cuestión es: ¿nuestra institucionalidad y nuestros conceptos sirven o no a la seguridad alimentaria? Aspiramos a que Colombia avance hacia una decisión colectiva que garantice que cada una de sus familias y que cada persona sean reconocidas inmediatamente en su dignidad humana, incluso reducida a su mínima expresión material: los mínimos vitales. Sabemos que en el camino de lucha deben evidenciarse algunos conceptos y alguna praxis. Daremos una leve mirada institucional; luego, una conceptual y plantearemos una propuesta: apostar por la construcción colectiva de un imaginario, no tanto para afrontar la visión hegemónica que garantiza los "juegos del hambre", sino para construir en nuestra realidad soberanía alimentaria y seguridad humana.

An Applause for and Criticism of the Colombian Farming Industry

Abstract

$\bigwedge$ re the minimum vital elements possible in bicentennial Colombia? Aan open research considers this question and encourages writing articles containing criticism and other texts that propose immediate solutions to the problem of hunger in Colombia. The central question is: Do our institutions and concepts serve or contradict food security? We look forward to Colombia making a collective decision in order to guarantee that every family and person is recognized immediately in their human dignity, even at its minimum material expression: the vital elements.

On the road of struggle, evidence of certain concepts and praxis must be observed. First, we will present a brief institutional outlook followed by a conceptual one. Finally, we will formulate a proposal: to bet on the collective construction of an image, not so much to confront the hegemonic vision that guarantees hunger games but to build, in our reality, food sovereignty and human security. 
Mots-clés

Minimum Vital ; Sécurité Alimentaire ; Dignité Humaine ; Production Alimentaire ; Sécurité Humaine.
Un applaudissement et deux critiques de l'agro-système colombienne

Résumé

Est-ce que sont possibles du minimum vital en Colombie Bicentenaire?

EUne recherche ouverte aborde cette question et motive à des textes critiques, qui proposent une solution immédiate à la question de la faim en Colombie. Le nœud de la question: Est-ce-que nos institutions et concepts servent ou contredisent la sécurité alimentaire? En espérant que la Colombie progrès vers une décision collective qui garantit aux familles colombiennes, être reconnu immédiatement, chaque personne dans leur dignité humaine, même il réduit à une expression matérielle minimum, le minimum vital: On sait que le chemin de la lutte, certains concepts et la pratique, doivent être attestés. On donne un léger aspect institutionnel. Puis, conceptuel. On peut demander une proposition: Miser sur la construction collective d'un imaginaire, non pas tant pour faire face à la vision hégémonique qui garantit les jeux de la faim, mais de construire, dans notre réalité: La souveraineté alimentaire et la sécurité humaine.

Um aplauso e duas críticas ao agro colombiano

Resumem:

São possíveis os mínimos vitais na Colômbia bicentenária? Uma pesquisa aberta aborda esta pergunta e motiva para a escrita de críticas e outros textos que proponham uma solução imediata ao tema da fome na Colômbia. 0 quid da questão é: nossa institucionalidade e nossos conceitos servem ou contradizem a segurança alimentar? Aspiramos a que a Colômbia avance para uma decisão coletiva que garantisse a cada uma das suas famílias, seja reconhecida imediatamente, cada pessoa, na sua dignidade humana, incluso reduzida à sua mínima expressão material, os mínimos vitais: sabemos que no caminho da luta alguns conceitos e práxis devem ser evidenciados. Daremos uma leve olhada institucional. Logo depois, uma conceitual. E faremos uma proposta: apostar pela construção coletiva de um imaginário, não tanto para afrontar a visão hegemónica que garante os jogos da fome senão para construir, na nossa realidade: soberania alimentar y segurança humana.

\section{Aplauso al campesino}

Antes de formular un par de críticas al agro aspiramos, como "ciudadanos de la ciudad", expresar reconocimiento y a dar las gracias públicamente - y quisiéramos con hechos - al "ciudadano del campo" y a quien comparte, día a día, tantas injusticias, indiferencia y violencia que le amenazan: su familia campesina. De entrada, reconocemos el problema de etimología por el cual el término "ciudadano" parece provenir de "ciudad". Para equilibrar lo anterior, observemos: nuestra cultura proviene de lo que cultivamos, de nuestro campo y su gente, lo que en Colombia incluye comunidades afrodescendientes y pueblos indígenas. Ahora, más allá de orígenes de las palabras, hay aspectos de fondo por los cuales los "ciuda- danos de ciudad" nos podemos llegar a pensar superiores a los "ciudadanos del campo", razones por las que quizás muchos de los hijos de nuestros actuales campesinos ya no aspiran a cultivar los campos ni a sembrar ni a recoger las cosechas. Por tanto, siendo los autores hombres maduros, profesionales e intelectuales, expresamos nuestra ambición de ser campesinos, de merecer serlo, de darnos vida y dar vida a otros con nuestro trabajo en el campo.

Que no parezcan extrañas algunas afirmaciones personales desde una mirada académica; estamos convencidos de que quizás convenga abordar así el desafío de la concepción convencional de ciudadanía (Molina, 2014) ante la universalidad y la igualdad pretendidas de tal 
concepto. Las concepciones pasan por lo que piensan o les hacen pensar a las personas.

De este modo, una mirada a la realidad del campo de nuestro país y a quienes en él han trabajado durante años vislumbra que tal ciudadanía es negada. Y mediante una institucionalidad centenaria, Colombia, nuestro Estado-nación, cuatrienio a cuatrienio ha negado en la praxis la ciudadanía al campesino. Esto pese a nuestro "esencialismo jurídico" y la ambivalencia de quienes anuncian el ejercicio de los derechos de los campesinos y así les reconocen, de dientes para afuera, su ciudadanía, la cual se mantiene "contradicha por los efectos de desigualdad y exclusión que en la praxis histórica predominan" (Molina, 2014, p. 88).

¿Suenan más extrañas nuestras afirmaciones? ¡No lo creemos! En el 2016 liberamos una investigación abierta mediante la cual hemos pretendido realizar un aporte a la construcción de un imaginario de mínimos vitales y seguridad alimentaria y así "desarrollar intuiciones que en el contexto nacional apenas se están abriendo camino" (Molina, 2014).

Ante nuestros campesinos, quienes llevan décadas de "no contar con el derecho a tener derechos" (Dagnino, 2014; Molina, 2014), recordemos lo que Michael Walzer llama el bien público primero: la pertenencia (Socolovsky, 1996, p. 297; Navarrete, 2006, p. 246). Más que frases retóricas y discursos en donde algunos proclaman, en busca de votos, que los campesinos auténticamente pertenecen a nuestra nación. Afirmamos que aspiramos a ser campesinos, a aprender de ellos, a ser uno más; quizás otros tantos también lo hagan.

En el imaginario de mínimos vitales propuesto, si Colombia no se declara orgullosamente campesina, no volverá a haber campo productivo, no habrá territorio aunque haya tierra, tampoco habrá nación y, por supuesto, se mantendrá el hambre y no habrá mínimos vitales para todos. Por lo tanto, proponemos afirmar con hechos que los campesinos sí pertenecen a nuestra nación y sí suman "como miembros legítimos y valiosos para ella” (Molina, 2014).

Cuando un presidente citadino afirmó en el 2013 "tal paro nacional agrario no existe", fue claro para otros ciudadanos que los campesinos invisibles sí existían. Así es que la unidad en la lucha común comienza a contrariar un hecho notorio e histórico, pues "aunque en el papel se dice que por su calidad de nacionales [los campesinos] son ciudadanos, en los hechos [...] se les priva de todo tipo derechos instaurados en la figura de la ciudadanía" (Molina, 2014, p. 92).
De hecho, desde un anticipo de la investigación en curso "La Construcción de ciudadanía en Colombia 1990-2012. El sujeto político en disputa”, propuesta por Jesús María Molina Giraldo, podríamos decir que la negación de los mínimos vitales de tantos sería prueba reina de que "esa igualdad propuesta por el modelo convencional de ciudadanía queda seriamente cuestionada entonces desde esos otros" (Molina, 2014, p. 93). La situación problema a resolver se amplía puesto que Colombia es más rural de lo que parece (INDH, 2011).

De esta manera, urge aprovechar estos momentos finales de bicentenario para construir un imaginario de mínimos vitales y esforzarnos en recordar a los ricos, con T.H Marshall citado por Molina (2014), que no "igualar a los integrantes de una sociedad en unos mínimos de bienes, rentas y derechos" hace menos claro el "horizonte de hacer aceptable y legitimar la estructura de desigualdad existente entre clases" (p. 93). Así mismo, esforzarnos por recordar a los pobres que incluso reconocer este límite con la injusticia es un destino demasiado precario frente a los principios ya acordados como fundantes de nuestra nación en 1991; el primero de ellos, la dignidad humana.

También es pertinente recordar tanto a ricos como a pobres que, en un cruce de caminos, en un solo paso nos orientamos hacia la dirección correcta o no y, así mismo, condicionamos a todos los demás; si tenemos claridad podríamos optar por un desarrollo auténtico. En resumen, ante un ciudadano campesino concebido para "mantener las desigualdades" proponemos un campesino a quien le permitamos cultivar nuestra soberanía alimentaria.

Como una de varias ideas que podrían consensarse está: "promover diferentes formas de producción de agroalimentos regiolocales como resistencia a la homogenización globalizadora de las mulinacionales" (Betancourt García, 2015, p. 136). Un imaginario de mínimos vitales podría dar algún aporte aunque no podamos impedir con decisiones locales ese proceso global que sigue entregando "el control que tienen en el interior de la cadena alimentaria las empresas multinacionales, en términos de la disponibilidad, la distribución y el acceso a los alimentos [y que en consecuencia nos] lleva a un proceso centralizador, concentrador y de mayor dependencia de los alimentos" (Betancourt García, 2015, p. 157).

En un país de las características y la vocación agroalimentaria de Colombia un imaginario compartido y construido desde abajo tendría el poder de limitar los impactos nefastos que está teniendo dicho proceso sobre nuestra soberanía alimentaria. Asociamos lo anterior 
con la lección escuchada de algún decano que sugería escribir kampesino (con k) e invitaba a construir la nueva realidad de un campesino en Colombia y así proponía uno que no respondiera al concepto de "pobrecito" sino uno que - con el desarrollo de una vocación que más que personal sea familiar - dedica su vida a cultivar la tierra para sí y para los demás. No se trata solo de revertir "esta afectación a los productores de agroalimentos en el siglo xx (años cincuenta y sesenta) [...] o de afrontar la desaparición de numerosas explotaciones campesinas por la vía de la violencia y que se mantiene desde la década de los noventa hasta hoy" (Betancourt García, 2015, p. 157).

Claramente, Colombia no puede renunciar al trabajo en 300000 unidades de producción de alimentos ni permitir el triunfo de los violentos sobre los despojados como si no hubiese Estado. Hay que hacer algo junto con los despojados frente a los datos y los registros oficiales de la acción social de la Presidencia de la República que dan cuenta de que hemos sobrepasado la cifra de " 256480 jefes de hogar que afirman haber dejado abandonados 270680 bienes inmuebles (predios), cuya área se calcula en 6556978 hectáreas" (Betancourt García, 2015, p. 158).

Hemos de disminuir los 2 millones de hectáreas que Colombia entregó a los pastos y malezas, también hay que reversar y superar esos 7 millones de hectáreas de tierra (Betancourt García, 2015, pp. 196-200) que le quitaron al pueblo de Colombia los despojadores y quienes con violencia desplazan -incluso a veces con apoyo de las fuerzas del orden cuando algunos aceptan traicionar su misión de paz y orden para todos-. La defensa de la vida y la propiedad incluye las del pobre y no solo las del rico.

No podemos seguir permitiendo que el Estado sea liderado por corruptos - traidores del bien común- o por líderes débiles - sin fuerza moral - que permiten el desplazamiento cuando su misión es proteger. Hay que recuperar a las personas y a las familias con vocación campesina y hay que idear estrategias que condicionen o que incluso determinen que se reverse dicha tendencia a la concentración de tierra en Colombia, como bien señala Machado (2003, p. 137), al menos para las últimas seis décadas. Pero al reconocer que "la acumulación por desposesión es base del conflicto por la tierra” (Betancourt García, 2015, p. 183), la propuesta no podría ser simplemente volver al pasado ni mucho menos legalizar el delito.

Revertir, restituir y reaccionar ya no sería suficiente. $\mathrm{Ni}$ latifundios ni minifundios, salvo que sean productivos y aseguren la soberanía alimentaria de las presentes y futuras generaciones. Planteamos acordar el futuro los planeadores de nuestras ciudades, con nuestros campesinos actuales y con los herederos de pequeñas y medianas parcelas —viudas y quizás muchos huérfanos-, reconociendo su dignidad y, con ellos, a cualquier otra familia que decida construir seguridad alimentaria y soberanía de los alimentos para nuestra nación. Ser campesino no ha de ser un destino de pobres elegidos por el abandono, sino de cabezas de familia y familias completas que responden a una vocación.

Sin violencia, con fuerza legítima y con acuerdos libres - paramétricos si se quiere-. ¿Será que no nos alcanza la tierra o la inteligencia para producir un modelo así? Quizás el kampesino que proponemos tenga algo más para decir respecto al emprendimiento que "se materializa con la creación de empresa que contribuye al crecimiento y desarrollo económico de cualquier país" (Buitrago, 2014, p. 7). Creemos que nuestra institucionalidad, incluido el Ministerio de Agricultura, al que enseguida formularemos una crítica, podría aportar mucho más de lo que ha entregado durante sus primeros cien años de existencia con sus fugaces ministros. Al fin y al cabo: "las políticas públicas tienen un impacto ya sea positivo o negativo sobre el emprendimiento" (Buitrago, 2014, p. 7).

El tema de la transparencia también debe ser mejorado. Un acuerdo sobre mínimos vitales, un consenso para eliminar el hambre y crecer en seguridad humana, puede mejorar nuestro indicador de transparencia nacional (ITN) que hoy marca, con dedo acusador, tal institucionalidad. Si aspiramos a la satisfacción de mínimos vitales para todos, debe cambiar la débil transparencia del agro, sus tímidas sanciones a los corruptos y una manipulada institucionalidad ${ }^{1}$.

Hasta mayo de 2016, para el período 2013-2014 en el último ITN disponible, se observa que entre ochenta y cinco instituciones muestreadas son catorce las que clasificaron como de riesgo alto o muy alto, entre ellas: el Ministerio de Agricultura y Desarrollo Rural y el Instituto Colombiano de Desarrollo Rural (Incoder). Aun si fuera un simple problema de percepción y no de hechos reales de corrupción, nos indican la necesidad de trabajar más transparente y eficientemente.

También aparece la necesidad de reflexionar sobre la eficiencia y la equidad, variables en las que investigadores como Roberto Herrera Daza tienen el valor de reconocer como "tradicionalmente, la justicia social no

\footnotetext{
"La escala de evaluación va de cero (mínima transparencia) a cien (máxima transparencia), y el indicador nacional se obtiene con el promedio del resultado de la evaluación de las tres variables que lo componen" Esto es, transparencia sanciones e institucionalidad" (Díaz, 2013, p. 18).
} 
ha sido un punto focal en la economía, en su defecto, su principal preocupación ha sido el tema de la eficiencia." (Herrera Daza, 2013, p. 39). Y la ambicionada eficiencia económica la advierte relacionada con dos conceptos fundamentales: el óptimo de Pareto y el costo marginal. Partiendo del "consenso entre economistas" en el sentido de Pareto se considera una asignación eficiente "cuando no es posible reasignar los recursos existentes de tal forma que alguno(s) mejore(n) sin que otro(s) empeore(n)" (p. 39).

La carencia de mínimos vitales podría proponerse como un punto inaceptable de máximo empeoramiento o como una posición original y punto de mínimo a partir del que es indispensable crecer. Estamos ante un problema complejo y con tentaciones múltiples pues, así como "existe una cantidad infinita de óptimos posibles" (Herrera Daza, 2013, p. 39), la mano invisible parece seguir determinando incontables externalidades negativas. Para considerar más la complejidad, recordemos cómo Arrow en su "teorema general de la (im)posibilidad" nos demuestra la sin garantía de resultado en imponer la "lógica de la maximización del bienestar en los procedimientos de elección colectiva.” (Arrow citado por Herrera Daza, 2013).

Así no será extraño observar cómo en Colombia "la ausencia de un consenso, sumado a la ausencia de reglas claras en cuanto a los límites de la propiedad privada" (Romero y Sarmiento, 2014) pueda haber sido un freno. Podría ser el momento de ir construyendo un acuerdo creciente. Al avanzar en minifundio y en latifundio sin exigirles a sus defensores soberanía alimentaria, menos seguridad humana, respeto a las presentes y futuras generaciones, se agrava el futuro sin solucionar los problemas del presente.

En este sentido, construir reglas y abordar tales variables de institucionalidad y transparencia -incluso de eficiencia paretiana del agro y el aporte a nuestra economía - en un imaginario de mínimos Vitales, tendría mucho que aportar para la transformación de la realidad. Estimamos que un consenso, también en el agro, tiene la máxima capacidad de "orientar las transformaciones requeridas" en los espacios de las relaciones Estado-sociedad (CLAD, 2015).

\section{Balance crítico ${ }^{2}$ sobre la agricultura colombiana: lo institucional}

El hombre es dios cuando sueña, pero esclavo cuando cuenta. Los ministros de agricultura, sea cual sea el nombre asumido para el ministerio ${ }^{3}$, requieren tiempo para realizar su trabajo y, así mismo, los presidentes de la República junto con quienes han aceptado pasar a la historia como estrellas fugaces por el campo colombiano tienen una grave responsabilidad al aceptar ser flores de pocos días. Quizás en mayor grado los presidentes, al haber nombrado a los ministros y luego permitir o propiciar su cambio teniendo el poder y el conocimiento para evitarlo.

En tiempos breves la cosecha para una nación no pudo ser planeada ni esperada ni mucho menos recogida. Nuestra teoría es que muchos de los ministros de agricultura, más allá de sus conocimientos, talento, buena voluntad o ilustres nombres y familias, no tuvieron tiempo de planear ni de ejecutar. El fracaso de ellos ha sido el fracaso del agro en Colombia durante cien años.

Desarrollamos la intuición que alimenta el presente texto mientras preparábamos una tarea para un magister en administración pública. Esto conllevó a la medición de una variable baladí: la duración de los ministros de agricultura en Colombia. Pretendíamos dar una leve mirada institucional a la agricultura colombiana - o a una parte de ella- en la historia de la oficialidad y cabeza nacional del agro. Como carecíamos de datos oficiales, lo hicimos con datos de Internet. Al consultar Wikipedia encontramos algunos nombres y solo años sin fechas exactas; usamos los datos disponibles gracias al desconocido investigador quien las había publicado antes. Nos centramos entonces en tales datos cuantitativos. Asumimos algunas convenciones con la limitación de no conocer fechas exactas.

Llamamos corto plazo al período de un año o menos; mediano plazo, a un período de uno a dos años; $y$, arbitrariamente, largo plazo a un tiempo de gestión superior a dos años, aunque fuese un solo día. Bajo tales criterios aparecieron hechos notorios. Destacábamos cómo Colombia contaba con un total de ochenta y cinco períodos ministeriales en menos de un siglo desde el primer ministro de agricultura en 1914, el doctor Jorge Enrique Delgado hasta Juan Camilo Restrepo, quien ejercía el cargo en aquel entonces. Luego supimos que

\footnotetext{
2 El investigador colombiano Absalón Machado Cartagena es reconocido como autoridad en seguridad alimentaria en Colombia, incluso como investigador de talla mundial. Así lo presentan sus publicaciones y su obra. Sin embargo, ¡cuánta incoherencia hay en sus argumentos sobre soberanía alimentaria en Colombia! De allí que el título inicial de este aparte fuese "Crítica a Machado y a la agricultura: Io institucional".

3 De Agricultura y Comercio (1914-1938), de Economía Nacional (1938-1947), de Agricultura y Ganadería (1948-1953), de Agricultura (1953-1994), de Agricultura y Desarrollo Rural (1994-actual).
} 
nos equivocábamos, según datos oficiales el número de ministros iba en noventa y siete.

También fue un error estimar la media de tiempo de gestión para los ministros de agricultura ${ }^{4}$ de Colombia en una que no sobrepasaba los catorce meses. Lo cierto es que la realidad desborda la prudencia. De 1914 a 2014 habíamos tenido en promedio un ministro de agricultura por año. Obtuvimos a finales del 2013, mediante derecho de petición al Ministerio de Agricultura, datos ${ }^{5}$ más precisos con los que actualizamos la tarea. Publicamos aquí tales datos sobre la duración de liderazgos en el Ministerio de Agricultura especialmente para aquellos amigos a quienes les pueda parecer interesante reflexionar más y mejor sobre el agro, sobre nuestra tierra, nuestro huasipungo.

De fondo, invitamos a una revisión y a una síntesis de textos académicos sobre el agro, lo que es indispensable para la ubicación de la presente crítica que se reconoce puntual, que señala un solo aspecto y que se presenta como un argumento sobre la necesidad de construir el imaginario propuesto. Por supuesto que será indispensable no solo releer a Machado, sino también los trabajos del investigador Jesús Bejarano.

Así mismo, es necesario profundizar, por ejemplo, en el hecho de que en decisiones públicas y entre colectivos dotados de inteligencia toda falta de acuerdo es violencia ${ }^{6}$. También se deben considerar aportes que logran contemplar el siglo completo como el trabajo de Salomón Kalmanovitz y Enrique López y tantos otros. Reconocemos que construir y recorrer un índice de tales lecturas es un tránsito obligatorio para avanzar en las críticas que nos permitan pasar de advertencias y recomendaciones a las lecciones aprendidas y a los acuerdos.

\footnotetext{
4 Para esta tarea se sugiere realizar un análisis de los períodos de los secretarios de agricultura de los cincuenta municipios que más aportan o han apor tado al PIB agrícola de la nación a partir de los años noventa.

5 Autorizamos, entonces, a que se divulguen libremente los presentes datos asumiendo el equipo de investigación la responsabilidad por lo aquí presentado. La empresa de investigación mínimos Vitales sas los hizo disponibles en el canal público Wikipedia, ya con fechas exactas.

6 Un concepto útil al buscar propuestas de superación sería "la unidad del fenómeno de la violencia" (Bejarano, 1986, p. 30)

La Universidad Nacional editó en el 2011 una Antología sobre Jesús Antonio Bejarano. En particular el Volumen 3 - Estudios Agrarios (Tomo I. Desarrollo de la Agricultura). Colección Obra Selecta, de estudio obligatorio para investigadores que quieran hacer una comprensión integral.
}

Como ofrenda a la tierra de Colombia compartimos estas líneas que entregamos en momentos de bicentenario (2010-2019), recordando el centenario del Ministerio de Agricultura (1914-2014) y a sus líderes. Estimamos que realizar una leve mirada sobre en un aspecto tan puntual como los sucesivos cambios de Ministros de Agricultura podría ser útil y sirva también para acordar mejores caminos.

\section{La administración del agro en Colombia: coyuntura y perspectiva histórica}

Solo un par de ministros de agricultura llegaron más adelante a ser presidentes en vigencia de la Constitución de 1886. Se limita a dos el número de las mujeres en la dirección del ministerio, esto después de la constitución de 1991 y al menos dos generales han tenido el cargo. Veíamos con beneplácito en el estudio inicial que el número de efímeros ministros de los años sesenta y setenta venían a la baja, para observar con estupor desfilar tres ministros en el 2013 y un hermoso paro agrario lleno de dignidad, promesas, esperanzas y decisiones ante una añeja crisis, eso sí, súbitamente descubierta, publicada y revelada.

Al revisar hacia el pasado, tomamos nota de que la cartera fue suprimida durante una década (de 1923 a 1934) durante el fin de la hegemonía conservadora y al inicio de la hegemonía liberal. Sin embargo, los nombres de los ministros existen y, por tanto, dejamos a los historiadores y a otros investigadores conciliar tales hechos en principio contradictorios.

Asumidas las convenciones previas, la información sobre los ministros de 1914 al 2014 arroja que más de la mitad de los períodos ministeriales de agricultura han sido, de acuerdo con lo delimitado anteriormente, cortoplacistas. Una cifra cercana a la tercera parte de los ministerios - treinta y seis de noventa y nueve períodos ministeriales - podría pretender haber logrado tener un enfoque de mediano plazo. Lo expuesto, obviamente, requerirá investigaciones específicas para identificar variables, decisiones y mediciones de impacto real que lo confirmen.

El límite de tiempo para hacer gestión habla por sí solo. La cifra inicial era la cuarta parte — cuando nos faltaban nombres y teníamos solo el año de inicio y de finalización de gestión y no fechas exactas de períodos, era la cuarta parte- Pero al establecer la lista de nombres ${ }^{7}$ con fechas exactas, esta creció a 54 ministros cortoplacistas, esto es más del $50 \%$. 
Con el debido reconocimiento a la buena voluntad de los enfoques de corto y mediano plazo, asumimos que en general las políticas públicas en Colombia, y aún más las referidas al agro, necesitan enfoques de largo plazo que sean asertivos, viables, consensados e incluso inteli- gentes, que cuenten con criterios de eficacia y eficiencia. Por lo tanto, no es extraño que miremos con más simpatía a aquellos períodos ministeriales más largos y a aquellos gobiernos que los permitieron, incluso haciendo abstracción sobre si su aporte a que la tierra diese frutos fue

Tabla No 1: Ministros del agro cortoplacistas.

\section{Antes de la Constitución Polífica de1991, seis por década}

\begin{tabular}{|c|c|c|c|c|}
\hline 1918 & Simón Araujo & \multirow{26}{*}{$\rightarrow$} & $1918-1919$ & Esteban Jaramillo \\
\hline 1921 & Enrique Olaya Herrera & & \multicolumn{2}{|c|}{ Olaya fue luego Presidente: 1930-1934 } \\
\hline 1922 & Ignacio Moreno & & & \\
\hline 1934 & Marco A. Auli & & 1934 & Sinforoso Ocampo \\
\hline 1934-1935 & Jorge Gartner & & 1934 & Jorge Soto del Corral \\
\hline 1935-1935 & Bernardo Mora & & 1935 & Cristóbal Bossa \\
\hline 1936-1937 & Benito Hernández & & 1935 & Guillermo Londoño Mejía \\
\hline 1937 & León Cruz Santos & & 1936-1937 & Manuel José Vargas \\
\hline 1938 & Marco Aurelio Arango & & $1937-1938$ & Nicolás Llinás Vega \\
\hline 1941 & Mariano Rodán & & 1940-1941 & Miguel López Pumarejo \\
\hline 1941-1942 & Marco Aurelio Arango & & 1941 & Gonzalo Restrepo \\
\hline 1943-1944 & Moisés Prieto & & 1943 & César García Älvarez \\
\hline $1945-1946$ & José Luis López & & 1945 & Luis Tamayo \\
\hline 1947 & Roberto Marulanda & & 1946-1947 & Antonio María Pradilla \\
\hline 1947-1948 & Moisés Prieto & & 1947 & Guillermo Salamanca \\
\hline 1949 & Santiago Trujillo Gómez & & 1948 & Alfredo García Cadena \\
\hline 1950 & Juan Guillermo Restrepo & & $1949-1950$ & José Vicente Dávila Tello \\
\hline $1956-1957$ & Eduardo Berrío González & & 1956 & Hernando Salazar Mejía \\
\hline 1958-1959 & Augusto espinosa Valderrama & & 1957 & Jesús María Arias \\
\hline 1960Hugo & Ferreira Neira & & $1959-1960$ & Gilberto Arango Londoño \\
\hline $1961-1962$ & Hernán Toro Agudelo & & $1960-1961$ & Otto Morales beítez \\
\hline 1964-1965 & Gustavo Belcázar Monzón & & $1962-1963$ & Cornelio Reyes \\
\hline 1969-1970 & Armando Samper Gnecco & & $1965-1966$ & José Mejía Salazar \\
\hline 1976-1977 & Álvaro Araújo Noguera & & 1970-1971 & J.Emilio Valderrama \\
\hline 1980-1981 & Gustavo Deger Chadid & & $1977-1978$ & Joaquín Vanin Tello \\
\hline 1986 & José Fernando Botero Ochoa & & 1985 & Hernán Vallejo Mejía \\
\hline \multicolumn{5}{|c|}{ Luego de la Constitución Política de1991, dos por década } \\
\hline 1994-1995 & Antonio Hernández Gamarra & & 1995-1996 & Gustavo Castro Guerrero \\
\hline 2013 & Francisco Estupiñán & & & \\
\hline 2013-2014 & Rubén Darío Lizarralde Montoya & & & \\
\hline \multicolumn{5}{|c|}{$\begin{array}{l}\text { Nota sobre el ministro Lizarralde: } \\
\text { Los tiempos de gestión del ministro Lizarralde no le permitieron salir de la lista del cortoplacismo, apenas si logró } \\
\text { permanecer hasta el } 7 \text { de agosto de } 2014 \text {. }\end{array}$} \\
\hline
\end{tabular}

Fuente: Respuesta a derecho de petición del 14 de noviembre 2013. Ministerio de Agricultura. Elaboración de Osío (2017).

\footnotetext{
7 Convendría hacer un análisis especial sobre la gestión y los resultados de los diez períodos de ministros "repitentes" y sus tiempos totales de gestión: Armando Samper Gnecco (1.82), Gustavo Castro Guerrero (2.04), Hernán Vallejo Mejía (2.14), Jorge Gartner (1.80), Marco Aurelio Arango (1.14). Solo dos de ellos ganan la posibilidad de un enfoque largoplacista - si eso pudiera ser posible- en períodos ministeriales discontinuos.
}

efectivo o no, si fue para el bien común y la soberanía alimentaria o si estuvieron al servicio de élites económicas y políticas.

Al considerar los tiempos de gestión por ministro, asumimos que el ejercicio de la responsabilidad en un 
primer nivel requiere de una viabilidad en el tiempo. Es cierto que se requiere el conocimiento, la capacidad, la buena voluntad y un poco de fortuna robada a los dioses con base en las tres primeras cualidades, pero solo en un tiempo razonable es que una autoridad puede aspirar a lograr la prestación de un servicio a la patria. Lastimosamente son menos de diez los períodos ministeriales que pudieron proyectarse a largo plazo por un lapso total de 26 años (sobre 100). Esto significa que durante el primer centenario del ministerio solo una cuarta parte de los tiempos institucionales del agro en Colombia han tenido un enfoque de largo plazo.

Lo que ha sucedido con los tiempos de gestión desde 1914 hasta 2014 en el Ministerio de Agricultura ayuda a hacer entendible lo que ha pasado con nuestro agro y podría ser una de las causas del magro resultado de un centenario de gestión. ¿O habrá un académico de peso que sostenga que los resultados del primer centenario del agro en Colombia son relevantes? Sin duda debe haber resultados, no todas las ideas las aporta la cabeza, el ministro o un secretario de agricultura; el cuerpo también tiene memoria, por lo que determinar en cuáles gestiones ministeriales o en qué décadas se ha direccionado mejor y con efectos a largo plazo sería otro análisis. Empero, pesa que el 90 \% de nuestros ministerios no hayan sido largoplacistas.

Si consideramos los ministros que incluye la lista cortoplacista $^{8}$, así como los restantes períodos no largoplacistas, podríamos llamarlos a todos juntos: tiempo perdido, tiempo sin dirección o tiempos breves o medianoplacistas que no tenían ambición de perdurar en su trabajo.

Presentamos a continuación una lista de 36 de 99 períodos ministeriales del agro calificados como medianoplacistas: ¡Una tercera parte! (tabla 2).

Presentaremos ahora la lista de honor: la de presunción de factibilidad real de gestión con enfoques de largo plazo (tabla 3). A falta de análisis más profundos y multi-variables, la lista de estos ministros que pudieron haber emprendido un camino y desarrollar un plan de trabajo dentro de una visión largo placista se presenta en el siguiente cuadro. Aun siendo esta una mirada puntual, lo sabemos, destacamos en tal lista solo nueve líderes capaces de mantenerse en el cargo y los presidentes que respectivamente lo permitieron.

Tabla No 2: Ministros del agro medioplacistas.

\begin{tabular}{ll}
\hline Anteriores a los sesenta & \\
\hline $1914-1915$ & Jorge Enrique Delgado \\
\hline $1916-1918$ & Luis Montoya Sotomayor \\
\hline $1924-1925$ & Gral. Diógenes A.Reyes \\
$1926-1928$ & Salvador Franco \\
$1938-1940$ & Jorge Gartner \\
$1944-1945$ & Carlos Sanz de Santamaría \\
$1950-1951$ & Alejandro Ángel Escobar \\
$1953-1954$ & Gral. Arturo Charry \\
$1957-1958$ & Jorge Mejía Salazar \\
\hline
\end{tabular}

Posteriores a los sesenta

\begin{tabular}{ll}
$1963-1964$ & $\begin{array}{l}\text { Virgilio Barco Vargas (luego } \\
\text { presidente de } 1986 \text { a 1990) }\end{array}$ \\
\hline $1966-1967$ & Armando Samper Gnecco \\
$1968-1969$ & Enrique Peñalosa Camargo \\
$1972-1974$ & Hernán Vallejo Mejía \\
$1981-1982$ & Luis Fernando Londoño Capurro
\end{tabular}

\begin{tabular}{|ll|}
\hline $1915-1916$ & Benjamín Herrera \\
\hline $1922-1923$ & Antonio Paredes \\
\hline $1925-1926$ & Carlos Bravo \\
\hline $1935-1936$ & Francisco Rodríguez Moya \\
\hline $1942-1943$ & Santiago Rivas Camacho \\
\hline $1948-1949$ & Pedro Castro Monsalvo \\
\hline $1951-1953$ & Camilo José Cabal Cabal \\
\hline $1954-1956$ & Juan Guillermo Restrepo \\
\hline
\end{tabular}

\begin{tabular}{|ll|}
\hline $1967-1968$ & Enrique Blair Fabris \\
\hline $1971-1972$ & Hernán Jaramillo Ocampo \\
\hline $1978-1980$ & Germán Bula Hoyos \\
\hline $1982-1983$ & Roberto Junguito Bonnet \\
\hline
\end{tabular}

Fuente: Elaboración propia de Osío (2017) con base en Respuesta a Derecho de petición del 14 de noviembre 2013. Ministerio de Agricultura. 
Tabla No 3: Ministros del agro largoplacistas.

\begin{tabular}{|ll|l|}
\hline $1919-1921$ & Jesús del Corral & $\begin{array}{r}\text { Período investigación } \\
\text { inicial mínimos vitales } \\
1992-2012\end{array}$ \\
\hline $1928-1930$ & José Antonio Montalvo & \\
\hline $1934-1934$ & Francisco José Chaux & Alfonso López M. \\
\hline $1974-1976$ & Rafael Pardo Buelvas & Virgilio Barco \\
\hline $1988-1990$ & Gabriel Rosas Vega & \\
\hline $1999-2002$ & Rodrigo Villalba Mosquera & \\
\hline $2002-2005$ & Carlos Gustavo Cano Sanz & Andrés Pastrana \\
\hline $2005-2009$ & Andrés Felipe Arias Leiva & Álvaro Uribe Vélez \\
\hline $2010-2013$ & Juan Camilo Restrepo S. & Álvaro Uribe Vélez \\
\hline
\end{tabular}

Fuente: Elaboración propia de Osío (2017) con base en respuesta a drecho de petición del 14 de noviembre 2013. Ministerio de Agricultura.

Así, más allá de estar de acuerdo o no con las variables de más impacto, ¡cuánta alegría nos da observar que ha habido posibilidades a un pensamiento de largo plazo para el campo y la agricultura en la última década! Esto al considerar el Plan Colombia para el campo, las políticas de seguridad democrática y las subsiguientes de prosperidad democrática y confrontarlas con políticas de seguridad humana o con las orientaciones e intereses reales de los diseños operativos de la seguridad alimentaria y nutricional. Lo anterior, particularmente bajo las presidencias de Andrés Pastrana Arango, Álvaro Uribe Vélez y el presidente actual, Juan Manuel Santos. No nos hace tal afirmación, necesariamente, ni pastranistas ni uribistas ni santistas. De hecho, con Juan Manuel Santos ese hecho positivo se mantuvo inicialmente, pero recibió un fuerte revés con la trilogía de ministros que se observaron en el 2013.

Estimamos como un hecho importante que se diseñen políticas idóneas consensadas incluso para el agro en el post-acuerdo con la guerrilla. Es claro: "lo que se negocia entre el Estado y la guerrilla no es en sí misma la paz para nuestro país, sino la terminación del conflicto [armado interno]" (Reyes Hernández, 2014, p. 17), pero relación tienen. Por tanto, es necesario superar la estigmatización de las familias campesinas. Para avanzar, una paz sostenible y creciente "requiere de condiciones mínimas" (Babativa, Jiménez, Pinzón, Parrado y Rey, 2014, pp. 48-49). En realidad pareciera que hubiéramos omitido esto al razonar sobre algo simple: la paz es un bien para toda la población, no solo para los excombatientes o las fuerzas del Estado.

Uno de los caminos para trabajar por la paz es hacer viable la seguridad alimentaria de la nación sin pretensión de restricción o de exclusión a las familias campesinas ni a los dueños del capital y / o latifundistas salvo, por supuesto, que posean propiedades fruto del delito, cuyo único destino ha de ser la expropiación y la entrega a dueños legítimos. De fondo, el problema que consideramos más fundamental es garantizar una capacidad sostenible y colectiva para que la tierra de frutos para todos, también por respeto y previsión a nuestras nuevas generaciones, consensando y normando un equilibrio que no permita establecer el monopolio de la tierra ni el imperio del minifundio, ni ahora ni nunca.

Con base en lo que se mencionó anteriormente sobre los tiempos de gestión, agregamos a nuestra propuesta que se debe evidenciar algo adicional: continuidad. Por supuesto, este único hecho aislado, podría ser insuficiente en sí, o incluso contraproducente, si lo que continúa es en el fracaso.

¿Tiene poca importancia el hecho de que en cien años del Ministerio de Agricultura en Colombia podemos contabilizar cien ministros que lo han dirigido? Pues a eso parece llevarnos el argumento en el cual se dice que "los cambios permanentes de ministro de agricultura no modifican la esencia de las políticas" (Machado, 2005, p. 14). Pues 
Tabla No 4: Ministros del agro largoplacistas con fechas

\begin{tabular}{|llllll|}
\hline Ministro (a) & Inicio & Cesación & En días & En años & Orden \\
\hline Jesús del Corral & 16 -mar-19 & 21 -nov-21 & 981 & 2.7 & 6 \\
\hline José Antonio Montalvo & 05 -feb-28 & 17 -may-30 & 832 & 2.3 & 13 \\
\hline Francisco José Chaux & 17 -may-30 & 29 -may-34 & 1,473 & 4.0 & 14 \\
\hline Rafael Pardo Buelvas & 14 -ago-74 & 19 -oct-76 & 797 & 2.2 & 72 \\
\hline Gabriel Rosas Vega & 14 -jun-88 & 06 -ago-90 & 783 & 2.1 & 84 \\
\hline Rodrigo Villalba Mosquera & 25 -ago-99 & 06 -ago-02 & 1,077 & 3.0 & 93 \\
\hline Carlos Gustavo Cano Sanz & 07 -ago-02 & 03 -feb-05 & 911 & 2.5 & 94 \\
\hline Andrés Felipe Arias Leiva & 04-feb-05 & 06 -feb-09 & 1,463 & 4.0 & 95 \\
\hline Juan Camilo Restrepo Salazar & 07 -ago-10 & 01 -jun-13 & 1,029 & 2.8 & 97 \\
\hline
\end{tabular}

Fuente: Elaboración propia de Osío, (2017) con base en respuesta a derecho de petición del 14 de noviembre 2013. Ministerio de Agricultura.

bien, nuestros argumentos contrarían así lo que el mayor experto colombiano en seguridad alimentaria considera sobre el cambio perenne de ministros de agricultura y quien parece identificarlo como un hecho baladí. Más evidente se hace el hecho cuando logramos contrastar el promedio de tiempo de gestión de los ministros en Colombia con el de los ministros en Estados Unidos ${ }^{9}$.

Lo anterior por el "mismo patrón de acumulación capitalista" y porque "en el diseño de políticas solo cambia la fuente prioritaria de la acumulación mercado interno o externo" (Machado, 2005, pp. 13-14). Creemos que ese es un peligroso discernimiento, ya que podría llevarnos a reducir la importancia del gerente nombrado por una empresa o del presidente elegido por un país, esto por análogos razonamientos a los de Machado. Es una simpleza que entra a compensar el mismo investigador Machado (2005) cuando luego reclama que "una buena comprensión de políticas exige conocer las opiniones de los beneficiarios, lo que no es posible sin trabajo de campo" (p. 14).

A continuación relacionamos las fechas exactas de inicio y de cesación de funciones de los nueve ministros que tuvieron períodos de gestión un poco más largos, esto es, de dos años o más: (ver tabla 4).

\footnotetext{
9 Sobre los tiempos de gestión de los ministros en Colombia, información pública que debe hacerse más pública, anotamos que solo una parte de dichos datos estaban publicados y, por tanto, la serie completa tuvo que ser adquirida mediante un derecho de petición en noviembre de 2013. Su contenido analizado y una lista actualizada de ministros de agricultura en Colombia fue hecha pública por el usuario Mínimos Vitales en Wikipedia. Se publicó en: http://es.wikipedia.org/wiki/Anexo:Ministros_de_Agricultura_de_Colombia. Esta lista puede confrontarse con esta lista similar con los datos de los secretarios de agricultura de Estados Unidos: https://en.wikipedia.org/wiki/United_ States_Secretary_of_Agriculture.
}

Identificamos a Machado como un investigador más asertivo cuando afirma que: "tampoco basta consultar los planes de desarrollo, los documentos conPES, las leyes y las normas, pues solo representan la intencionalidad política" o al señalar cómo "el conocimiento de las relaciones agente-principal $^{10}$ [-gremios, organizaciones sociales y políticas, pobladores rurales, grupos de poder-] es uno de los elementos útiles para interpretar las políticas" (Machado, 2005, p. 14). El autor precisa sutilmente cómo "el hecho de que un gobierno presente más documentos CONPES o expida más normas no significa que su política sea mejor que la de uno menos prolífico; tampoco significa que tenga un mejor conocimiento de la problemática sectorial” (Machado, 2005, p. 15). Para acotar estas afirmaciones podemos decir que un continuo cambio de ministros o secretarios de agricultura implica menos posibilidad de cultivar la tierra previamente arada. En relación con lo anterior, a continuación presentamos un argumento fuerte a partir de la referencia al líder mundial en producción: Estados Unidos.

Con cinco lustros más de existencia (de 1889 a 2014), la institución responsable del agro en Estados Unidos ha tenido treinta responsables, no cien como Colombia (1914-2014). Hemos calculado la media de los secretarios de agricultura de Estados Unidos ${ }^{11}$, no en catorce meses

\footnotetext{
10 "En economía, el problema del agente-principal designa un conjunto de situaciones que se originan cuando un actor económico (el principal o el jerarca), depende de la acción o de la naturaleza o de la moral de otro actor (el agente), sobre el cual no tiene perfecta información. En otras palabras, ese asunto concierne las dificultades que se presentan bajo condiciones de información asimétrica, cuando el principal contrata a un agente." (Problema del agente-principal, s.f.).

11 En la bibliografía se referencian los sitios webs referenciados respectos a listas de ministros de agricultura (Colombia) y de secretarios de agricultura (Estados Unidos)
} 
o en un año - como lo ha asumido útil el círculo vicioso a romper de la improvisación en Colombia por parte de nuestras élites económicas y políticas - sino en más de cuatro años.

Si consultamos el dato sobre el secretario de agricultura estadounidense del 2009 al 2016, vemos que se mantiene el mismo nombre: Tom Vilsack, la trigésima persona en ejercer el cargo, comenzó a hacerlo desde enero de 2009 y en mayo del 2016 continuaba con tal labor. Un trabajo avanza después de un tiempo considerable (meses, años, más de un lustro, quizás) completando una visión —cualquiera que sea, por ejemplo, pro MonSanto-. Y así como se ha evidenciado el avance en Estados Unidos y, como lo enuncia la lógica, el contra-recíproco se ha hecho efectivo en Colombia.

El ministro de agricultura número noventa y nueve en Colombia, Rubén Darío Lizarralde, no pasó del 7 de agosto del 2014, esto es, no logró completar doce meses a cargo del agro de nuestra nación. Sin embargo, es increíble que, según algunos reconocidos investigadores y académicos que se dedican al estudio del agro, esto parece no importar, pues "los cambios permanentes de ministro de Agricultura no modifican la esencia de las políticas" (Machado, 2005, pp. 13-14).

¿Será que para el éxito de las políticas del agro de Estados Unidos no importará que sus secretarios de agricultura duren lustros, incluso décadas? En cambio, muchos de los nuestros no completan un año. Business are business ${ }^{12}$, felicitamos la inteligencia de dichas élites del imperio; son productivas, sin que ahondemos aquí en el tema de los costos que asumen y su ética. Pero, asumiendo que existe un intangible llamado bien común, no sería inteligente: "supeditar la toma de decisiones públicas a las presiones o intereses políticos” (Páez, 2013, p. 4).

Las presentes líneas tienen un solo objetivo: proponer y convencer al lector, a cada investigador, a cada ciudadano en Colombia que se imponga un hábito en la Agricultura de Colombia, esto es, el bien común por encima de la politiquería, a fin de que un imaginario de mínimos

\footnotetext{
12 Presidentes como William McKinley, Theodore Roosevelt y William Howard Taft permitieron a James Wilson ejercer como secretario durante dieciséis años, del 5 de marzo de 1897 al 3 de marzo 1913. También podemos mencionar los casi ocho años permitidos en las gestiones de Eisenhower y Kennedy a los secretarios del Departamento de Agricultura, o los casi cinco años durante los mandatos de Roosvelt, de Reagan y de Clinton, o los más de cuatro de Obama en dicha continuidad de políticas permitida y real, lo que también asegura sus cabezas e incluso supera las diferencias naturales entre visiones partidistas de republicanos y demócratas.
}

vitales sea posible en el país y, por supuesto, la seguridad alimentaria.

En el mismo sentido, y en razón del proceso en el que los cultivos transgénicos y las semillas foráneas se cuestionan por unos y se alaban por otros, más nos preocupa que nuestras semillas adquieran dueños extranjeros de multinacionales que se apropian de ellas, las modifican y las acumulan como si fuesen capital. Nuestro futuro puede estarse guardando en cajas fuertes a las que no tenemos acceso.

El hecho de que los pueblos no mantengan propiedad de sus semillas ancestrales y que el Estado permita la renuncia a nuestras propias tradiciones de alimentación podría llevarnos a sugerir que se extienda un principio de precaución con los negocios que se les permita hacer a las multinacionales y con la apertura de las mismas. El bien común ${ }^{13}$ podría estar por encima de los negocios particulares de las élites económicas y políticas.

En cualquier caso, entre amenazas y promesas de paz por parte de las minorías de grupos violentos al firmar acuerdos, el liderazgo del ministro de agricultura ${ }^{14}$ seguirá siendo clave en el cumplimiento de lo pactado y para que la paz crezca con justicia, y no tanto al momento de firmar la paz. Tanto en los diálogos de La Habana como en la aún más difícil y no inmediata paz con los "Elenos" hay que trocar el acuerdo de paz en justicia social y la invitación de "patria o muerte" en "patria y vida". Si las minorías de violentos deciden hacer suya la institucionalidad colombiana, hemos de afrontar un tema coyuntural y de trascendencia histórica: acuerdos viables para generar y distribuir más comida, y no solo para acumular riqueza.

El valor agregado que se genera con la tensión continua entre fuerzas del capital y del trabajo ha de asegurar siempre los mínimos vitales para todos, sin exclusiones, sin dejar de premiar la iniciativa y minimizando el

\footnotetext{
13 Aportar al bien común no sería algo exclusivo del sector político público, también atañe al sector privado. Reconocer tal hecho ha conllevado a nuevas praxis en los modelos empresariales, como las redes de confianza que propone esta investigación abierta, figura propuesta para facilitar la generación de empleo en condiciones de legalidad y dignidad.

14 Al menos con las FARC la tierra es el primer punto del acuerdo e históricamente es el principal. En consecuencia, la "reforma rural integral" tendría cuatro pilares: 1) "Salto cuantitativo y cualitativo" mediante fondo de tierras para distribución. 2) "Programas especiales de desarrollo con enfoque territorial" mediante instituciones, comunidades y un sistema de incentivos. 3) Planes protección social para los campesinos. 4) Seguridad alimentaria y nutricional y programas especiales contra el hambre (El Tiempo, 2013).
} 
asistencialismo. Esto no será posible sin "mejorar la capacidad institucional” (Fajardo Pineda, 2014, p. 35). Hay que condicionar la propiedad, más que solucionar la pobreza con más posesión de tierra en minifundio ineficiente o en latifundio ocioso. Debemos afrontar "la carencia de capacidades" recordando que los ciclos de la pobreza no están "en la carencia de la renta" (Fajardo Pineda, 2014, p. 34).

El desarrollo de nuestra agricultura sería una manera de superar en paz una de las causas objetivas del conflicto $y$, sin plazo alguno, de superar inmediatamente esa injusticia que se esconde bajo un temible nombre: el hambre de nuestro pueblo. En tal sentido, posiblemente esta coyuntura determine al ministro de agricultura número cien o al siguiente como el más importante de la historia de Colombia.

Será necesario dar una mirada más profunda a otras variables al considerar algunas políticas y a sus frutos dado que no han sido objeto de estas leves búsquedas y críticas apenas iniciadas. Pero es más importante aún que no nos podemos quedar en los problemas y, en este caso, nuevamente a quien criticamos es quien nos ilumina.

\section{Las soluciones}

Machado (2002), al preguntarse ¿dónde pueden estar las soluciones?, lista cinco puntos referentes a la seguridad alimentaria, uno de ellos dice que "la reforma institucional es otro de los elementos claves para la seguridad alimentaria. Sin reglas de juego estables y acordadas, sin organizaciones públicas y privadas adecuadas para un desarrollo más endógeno, será difícil diseñar y operar estrategias de seguridad alimentaria" (p. 61). No podemos dejar de considerar incluyentes a las instituciones políticas y económicas propuestas por el par de economistas norteamericanos Acemoglu y Robinson (2012).

Afirmamos entonces: como los planes y estrategias requieren el largo y mediano plazo, solo las coyunturas y las tácticas deben resignarse al corto plazo. Aunque curiosamente Machado, Vásquez y Núñez (2005) pretendan dar poca importancia a los efímeros períodos ministeriales en el agro, también es el investigador Machado quien reconoce que "las políticas agrarias colombianas se han caracterizado por una alta inestabilidad, un manejo coyuntural y la inexistencia de una visión estratégica del sector agropecuario y rural" (p. 17).

A partir de lo anterior, coincidiendo con este último planteamiento ofrecido desde la academia y el sector rural, estas líneas de mirada institucional nos permiten un contexto para el problema de fondo que seguiremos abordando, variable resultado que guarda relación directa con nuestro objeto de investigación, a saber, los mínimos vitales en relación con la seguridad alimentaria.

No conocemos una respuesta razonable a la pregunta sobre por qué Colombia no come bien... aún. Y nos preguntamos si es viable construir tal explicación o justificación. Sobre la convicción alcanzada de que necesitamos avanzar en la construcción de un imaginario de mínimos vitales presentaremos argumentos en los textos que sean necesarios, aunque el concepto no sea originalmente nuestro. Fue el salvadoreño Alberto Masferrer con su texto El minimiun Vital (1997), quien formuló una propuesta ya desde 1914. Estimamos que el proyecto de Mínimos Vitales tiene vigencia todavía y que esta no es restringida al horizonte de un país. Este Imaginario aboga por más empleo, más consumo de productos de nuestras agro-cadenas y más eficiencia de las mismas, más acuerdos y menos asistencialismo.

Pues bien, si logramos pasar de identificar los problemas significativos de la estructura agraria colombiana a aplicar acciones concretas y consensadas, quizás el actual ministro de agricultura de Colombia, el número cien, o cualquier otro, podría avanzar en el camino de las soluciones. Además, si le permitimos a un ministro un poco más de tiempo para su gestión y lo dotamos de una política, un plan y un objetivo consensado, podría aportarnos mucho más que los precedentes, recordando el mockusiano "construir más sobre lo construido".

Desde el 2014, sin conocer quién sería el centésimo ministro de agricultura en Colombia lo invitamos a aportar desde lo institucional a la realización de la utopía - al menos en el país - de un imaginario de mínimos vitales. En el 2017 o 2018 — cuando ya se vislumbra la llegada de un ministro más- entendemos que más que un nombre o ciertas capacidades, Colombia necesita líderes para el agro con vocación de generar acuerdos: nuevos acuerdos cada vez más incluyentes y que, por supuesto, los desarrollen. Más que normas y más normas o largos acuerdos con cláusulas, se trata de re-construir en paz limitaciones informales de institucionalidad con las que hemos venido trabajando.

Proponemos avanzar de comunidad en comunidad con más principios consensados sobre la vida en el campo y dialogar sobre sus actuales costumbres de cultivo y producción. Como fruto de este diálogo - que no tendría que ser totalizante ni de obligatorio cumplimiento, sino particular y de libre albedrío- es posible avanzar hacia mejores hábitos, arriesgarse a cosas nuevas sin que 
ello implique más leyes que se ignoren y no se cumplan ni ejercicios de autoritarismo. Por ejemplo, podrían emerger propuestas para que cada municipio o región de Colombia aporte en la construcción de un imaginario de mínimos vitales; así como se podrían establecer límites a la propiedad de la tierra y condicionar su propiedad a su uso y sus resultados, proteger las fuentes de agua, preferir el consumo de productos autóctonos con un mayor valor nutricional, etc.

Estamos convencidos de que de algunos acuerdos explícitos, breves y profundos, luego de ser consensados, no tienen que llevarse al papel sino a la vida cotidiana. Así, el cumplimiento de estos se hace más obligatorio al ser incorporados y transmitidos socialmente y al hacer parte de la cultura (North, 1990). Claro, cada nuevo acuerdo y sus contenidos, serán posibles solo si el presidente, su ministro de agricultura y el pueblo de Colombia generan un diálogo dinámico, acuerdan acciones, hacen públicos tales pequeños acuerdos y los llevan a la práctica. ¿Lo harán? ¿Lo haremos? ${ }^{15}$

\section{Referencias bibliográficas}

Acemoglu, D. y Robinson, J. A. (2012). ¿Por qué fracasan los países? Traducción de Marta García Madera. Colombia: Editorial Planeta.

Anexo: Ministros de agricultura de Colombia. (s.f.). En Wikipedia. Recuperado el 7 de noviembre de 2016 de: http://es.wikipedia.org/wiki/Anexo:Ministros_de_ Agricultura_de_Colombia

Babativa, L., Jiménez, J., Moreno, J. L., Pinzón, C., Parrado, L. y Rey, A. (2014). Proceso de reinserción social en Colombia. Expectativas y realidades, caso de estudio Villavicencio y las FARC-EP. Política \& Administración, 26, 42-49.

\footnotetext{
15 Toda la investigación de la que resultó este artículo es fruto de un equipo. Se obtuvieron los datos del Ministerio de Agricultura con un derecho de petición presentado por Alicia Jaramillo, quien además ayudó a darle claridad y a mejorar la redacción del texto. Laura Pérez, quien, además de elaborar las líneas de tiempo, detectó errores, aportó críticas y produjo un draft paper de difusión de la presente investigación. La necesidad de seguir trabajando el tema y generar nuevos textos enriquecidos con el consenso nos hace subrayar el concepto de colectivo, tácito en la propuesta de una investigación abierta. Y, ante las comprensiones alcanzadas que deben seguir siendo ampliadas o cuestionadas, creemos que es necesario asumir la falsabilidad de nuestras conclusiones y así no cerrar el diálogo.
}

Bejarano, J.A. (1986). La Violencia y las Transformaciones Sociales, 3era. Conferencia. Procuraduría General de la Nación.

Bejarano, J. A. (2011). Volumen 4. Estudios de historia e historiografía. Tomo I. Historia Económica. Bogotá: Universidad Nacional de Colombia.

Betancourt García, M. (2015). Política de seguridad alimentaria nutricional (SAN) y Desarrollo Territorial en Colombia. (Tesis doctoral). Universidad Complutense de Madrid e Instituto Universitario de Investigación José Ortega y Gasset. Madrid.

Buitrago Nova, J. A. (2014). Emprendimiento en Colombia. Administración y Desarrollo, 59 (43), 7-21

CLAD. (2015). Revista del CLAD Reforma y Democracia es indizada en Redalyc. Recuperado de: https://www. clad.org/noticias/27-contenido-destacado/314-revista-del-clad-reforma-y-democracia-es-indizada-en-redalyc.

Dagnino, E. (2004). ¿Sociedade civil, participação e cidadania: de que estamos falando?. En, D. Mato (coord.). Políticas de Ciudadanía y sociedad civil en tiempos de globalización (pp. 104-105) Caracas: FACEs, Universidad Central de Venezuela.

Díaz, I. C. (2013). La democratización y la participación ciudadana, fundamentos para el fortalecimiento del alto gobierno en la construcción y desarrollo de políticas públicas. Administración y Desarrollo, 57 (41), 11-30.

El Tiempo. (27 de mayo de 2013). Santos explica los 4 pilares de la reforma rural tras acuerdo con FARC. Recuperado el 27 de mayo de 2013 de: http://www.eltiempo.com/ politica/los-pilares-de-la-reforma-rural-tras-acuerdo-con-farc_12827707-4.

Fajardo Pineda, O. D. (2014). Los subsidios a la demanda a través de asignaciones directas a las personas en condición de vulnerabilidad en Colombia: un análisis desde el concepto de capacidades y el desarrollo humano. Revista estudiantil Política \& Administración, 26, 30-35.

Herrera Daza, Roberto. (2013). La eficiencia y la equidad en los sectores público y privado: economía distributiva y justicia social. Administración y Desarrollo, 58 (42), 39-57.

Machado, A. (coord.) (2002). Desarrollo rural y Seguridad alimentaria. Un reto para Colombia. Universidad Na- 
cional de Colombia ; Red de desarrollo rural y seguridad alimentaria (RESA).

Machado, A. (2003) Ensayos sobre seguridad alimentaria. Bogotá: Universidad Nacional de Colombia; Red de desarrollo rural y seguridad alimentaria (RESA).

Machado, A., Vásquez, R. y Núñez, L. (2005). La Academia y el sector rural. Bogotá: Universidad Nacional de Colombia, CID.

Masferrer, A. (1997). El Mínimum vital. El Salvador: Editorial Clásicos Roxsil.

Ministerio de Agricultura. (2013). Respuesta a derecho de petición presentado por el equipo de investigación de Mínimos Vitales: Relación Ministros de Agricultura de Colombia desde su creación en 1914.

Molina Giraldo, J. M. (2014). Aportes para pensar la ciudadanía. Por una crítica a su concepción convencional. Administración y Desarrollo, 59, (43), 87-97.

North, D.C. (1990). Institutions, Institutional Change and Economic Performance. Cambridge: Cambridge Univ. Press.

North, D.C. (1993). Instituciones, cambio institucional y desempeño económico. FCE. Recuperado de: http:// www.cepal.org/ilpes/noticias/paginas/4/15434/ north90.doc.
Osio Uribe, H.G. (2017). Imaginario de mínimos Vitales: aporte para su construcción desde la Seguridad Alimentaria en la Colombia bicentenaria. (Tesis de Maestría). Escuela Superior de Administración Pública.

Parra Ramírez, E. (2013). Editorial. Administración y Desarrollo, 58, (42), 3-4.

Páez, P. N. (2013). Editorial. Revista Administración y Desarrollo, 57, (41), 3-4.

PNUD. (2011). Colombia rural: razones para la esperanza. Informe Nacional de Desarrollo Humano 2011. Bogotá: INDH, PNUD.

Problema del agente-principal (s.f.). En Wikipedia. Recuperado el 24 de noviembre de 2012 de: http://es.wikipedia.org/wiki/Problema_del_agente-principal

Reyes Hernández, D. M. (2014). ¿Y después de la guerra qué? Revista estudiantil Política \& Administración, 26, 16-21.

Romero, T. y Sarmiento, H. (2014). El dilema social de la política integral de tierras: derecho a la propiedad vs bien común. Revista estudiantil Política \& Administración, 26, 36-41.

United States Secretary of Agriculture. (s.f.). En Wikipedia. Recuperado el 7 de noviembre de 2016 de: http:// en.wikipedia.org/wiki/United_States_Secretary_of_ Agriculture 